\title{
Evaluation of structural safety and seismic vulnerability of historical masonry buildings: studies and applications in the Tuscany Region
}

\author{
S. Caprili, F. Mangini \& W. Salvatore \\ Department of Civil and Industrial Engineering, University of Pisa, Italy
}

\begin{abstract}
Recent earthquakes in Italian regions evidenced the high vulnerability of historical masonry of existing buildings: severe damages were revealed in structural and non-structural elements with the ensuing loss of lives and of significant examples of the Italian architectural tradition, often requiring a strong financial commitment to take them back to their former glory. The majority of Italian building's heritage is made up of masonry constructions with high architectural, historical and monumental impact, enlarged over the centuries without an organized scheme and consequently characterized by structural and non-structural problems often increased by the lack of accurate maintenance. The Italian Standards for Constructions and the guidelines provided by the Ministry for Infrastructures for the evaluation and reduction of seismic risk on historical heritage pays a lot of attention to the vulnerability analysis of existing buildings, necessary for the development of a project to provide a high level of structural static and seismic safety without deleting the original nature of the building. In the present paper, the structural analyses of two historical masonry buildings, Palazzo La Sapienza in Pisa and Palazzo Ducale in Massa are presented.

Keywords: cultural heritage, masonry buildings, vulnerability assessment, local collapse mechanisms, global behaviour.
\end{abstract}

\section{Introduction}

Recent and past seismic events that stroke Italy during the last decades (for example Friuli 1976, Irpinia 1980, Umbria-Marche 1997, L'Aquila 2009, and 
Emilia-Romagna 2012) highlighted the high vulnerability of the historical masonry cultural heritage, characterized by buildings realized without the following of specific seismic prescriptions and usually adopting different and overlapping construction techniques. The analysis of damage scenarios evidenced the need to adopt suitable strategies for modifying, improving or locally reinforcing structures, without altering their original characteristics but providing a significant residual margin of structural safety, especially taking into account the activities actually developed inside those building, used to house schools, Government offices and other public functions.

One of the main problems affecting historical masonry buildings is related to their origin and development; during the centuries, such structures underwent severe modifications, expansions, enlargements and super-elevations that transformed their original configuration of single buildings into structural aggregates, made up of different parts connected together without specific devices and not necessarily working in a global way, with the possible following activation of local collapse mechanisms especially in presence of dynamic actions, such as overturning of façades, tilting of corners and so on.

According to current Italian, European and international standards for constructions [1-3], the vulnerability analysis of masonry buildings (and the following organization of the retrofit interventions - both at global or local level) shall be executed through a multi-level approach that includes geometrical and structural survey, mechanical characterization of material and foundation soil, modelling and analysis of the structure and execution of safety checks as a function of the Knowledge Level and of the related Confidence Factor reached. This approach, commonly adopted for "ordinary" structures, can be extended to historical and monumental buildings by accounting for their greater complexity and the following need of a very deep level of knowledge.

A number of examples of evaluations of the seismic behaviour of monumental buildings are presented in the current scientific literature [4-8]. Oliveira [9] strongly discussed the problem of the numerical modelling of complex buildings, evidencing the possibility to adopt many different approaches (linear and nonlinear one-dimensional models for individual elements, 2-D and 3-D models for entire building complexes, etc.), as well as the difficulty to determine the most appropriate methodology for each specific case. Despite the ever-more refined and accurate numerical models in fact, significant uncertainties remain regarding the correct representation of the materials' mechanical properties and the dynamic behaviour of the entire building or portions thereof.

In this context, Italian Technical Regulations for Constructions [1], together with the "Guidelines of the Ministry of Culture and Heritage" [10], underlines the necessity to analyze, beside the global behaviour of structural aggregates, the activation of local collapse mechanisms of significant structural portions, identified on the base of the critical points and of the cracking scenario revealed during the in situ survey. Figure 1 shows the general scheme that shall adopted for the assessment of historical buildings, accounting for the multi-level procedure previously mentioned and including, as final step of the approach, the eventual retrofit. 


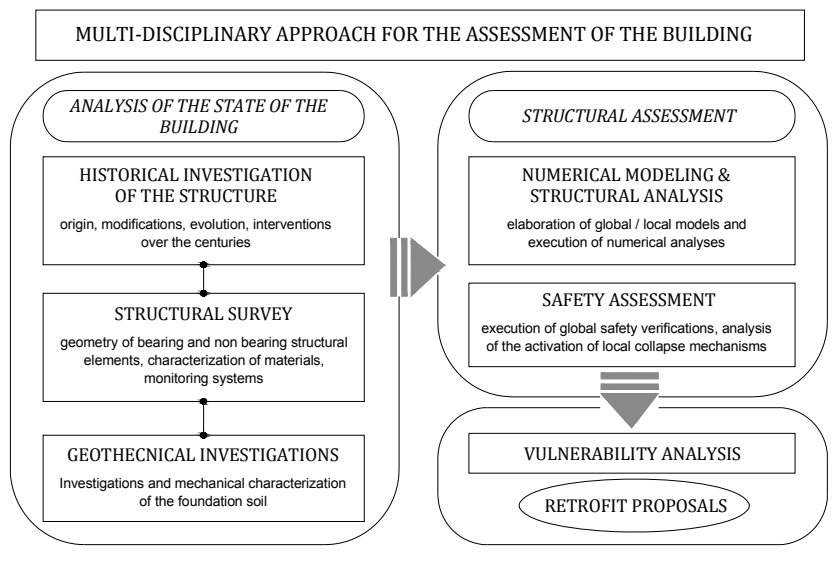

Figure 1: Scheme of the adopted methodology - integrated approach.

In the present paper, the attention is mainly focused on the analysis and safety checks, since further investigations are already under execution, of two historical buildings in Tuscany: Palazzo La Sapienza in Pisa and Palazzo Ducale in Massa.

\section{Description of the two case study buildings}

\subsection{Palazzo La Sapienza in Pisa}

The building, originated from the medieval structures of Piazza del Grano and of Dogana del Sale, was extended during the XV century to house the seat of the University of Pisa and all the connected services. Significant modifications to the original configuration of the building were introduced during the XIX century, as a consequence of the increase of the University Library; the demolition of many internal bearing walls, the super-elevation of the west part of the building of about $3.0 \mathrm{~m}$, the modification of shape and dimensions of doors and windows, the realization of new storey slabs and others leaded to structural diseases in several parts of the building, evidenced by a wide cracking scenario. Between 1928 and 1929, the western part of the building was raised up reaching the height of the adjacent parts: this intervention finally transformed the original Renaissance structure of the Palace, made up of a relative small volume of two storeys into the actual massive three storey building (Figure 2). The detailed description of the morphological development of the building is presented in [11]. Nowadays, the building presents a trapezoidal plan with three floors above ground and a gable roof whose garret accessible for maintenance. The plan dimensions are $80.0 \mathrm{~m}$ by $53.7 \mathrm{~m}$, while the central courtyard, surrounded by a ground-level colonnade and a first-floor arcade running parallel to the ground floor sides, has maximum dimensions of $35.5 \mathrm{~m}$ by $21.2 \mathrm{~m}$. Different vaulted surfaces (i.e. cross and cloister vaults, some of them with lunettes) and various types of floor slabs (steel elements 
with different profiles) are present; the useful height of the ground floor varies from $4.30 \mathrm{~m}$ to $5.50 \mathrm{~m}$. The situations are similar on the first and second floors, where the maximum heights attained are respectively equal to $5.60 \mathrm{~m}$ and $5.20 \mathrm{~m}$. Figure 3 shows the ground floor of the building with the indication of the construction period of the different portions.
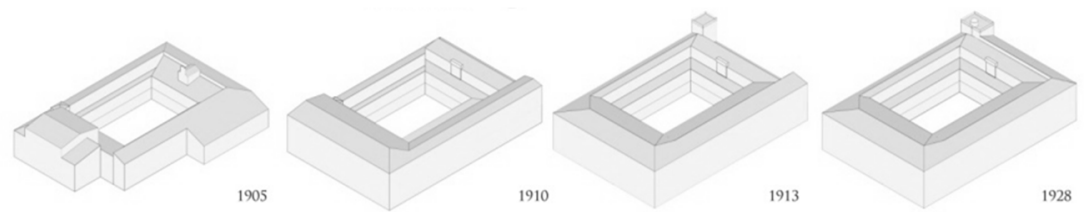

Figure 2: Volumetric evolution of Palazzo La Sapienza during the XIX century.

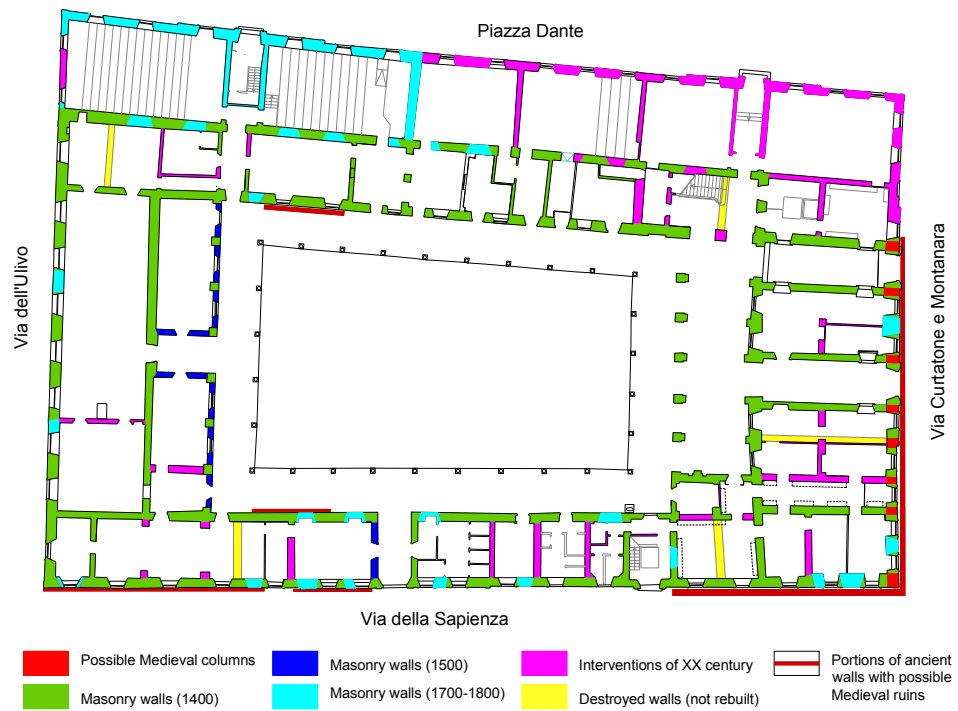

Figure 3: Evolutive development of Palazzo La Sapienza (ground floor).

\subsection{Palazzo Ducale in Massa}

Palazzo Ducale in Massa, actually used for the Prefecture and of the District Office, was originally built in 1563 by the willing of Alberico I Cybo-Malaspina, on the base of a very small sized pre-existent construction used for hunting and fishing developed on two storeys. During the XVI century several modifications were applied to the original structure of the building; for example, one storey was added to the main structure trying to provide a global continuity to the main facade of the complex. Other modifications were executed during the next centuries, finally resulting in the actual "structural aggregate", simply schematized in the 
Figure 4 and Figure 5, in which the evolution of the ground floor is briefly summarized.
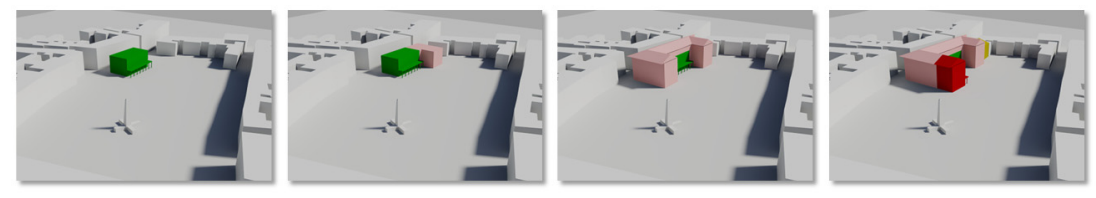

- $1100 \mathrm{~d} C$

- $1500 d \mathrm{C}$

- $1600 \mathrm{~d} . \mathrm{C}$.

- $1700 \mathrm{~d} . \mathrm{C}$
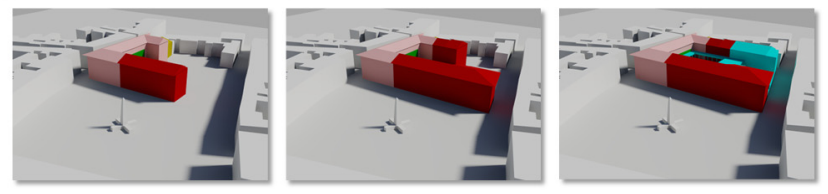

Figure 4: Volumetric evolution of Palazzo Ducale over the centuries.
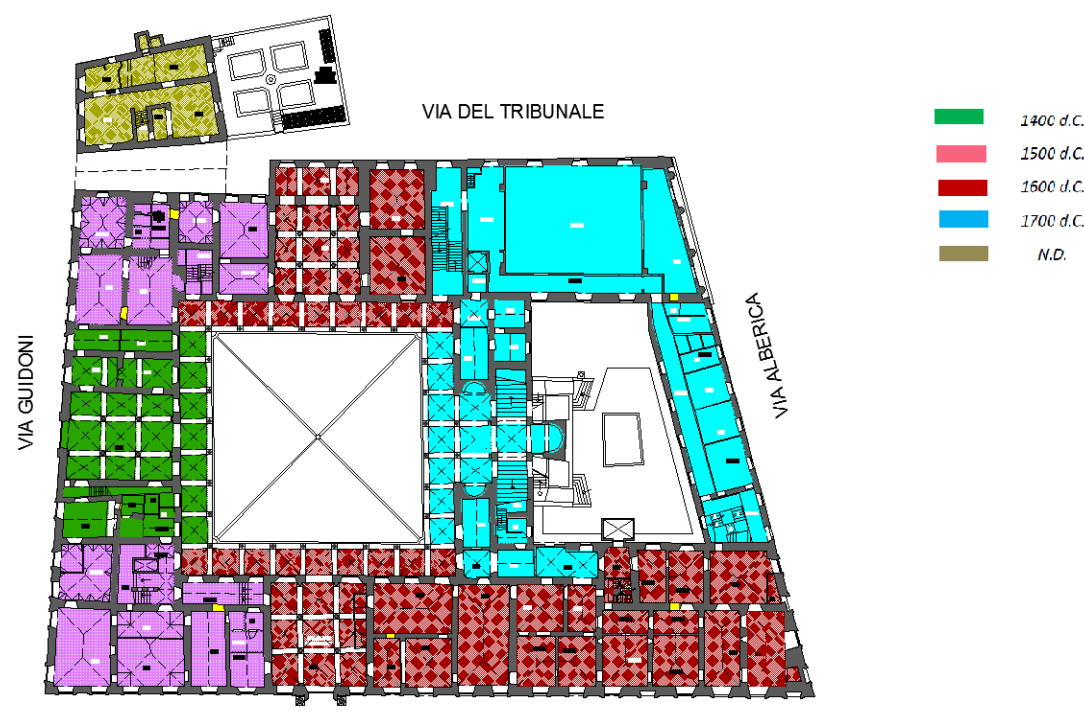

PIAZZA ARANCI

Figure 5: Evolutive development of Palazzo Ducale (ground floor).

Nowadays, the building is organized around two internal courts (of area respectively equal to about $890 \mathrm{~m}^{2}$ and $400 \mathrm{~m}^{2}$ ) and develops into three main floors that house the offices, the Prefect's house and other functions; two additional levels, i.e. the attic and the basement, are used for technical activities, recovery of materials and others. The interstorey height strongly varies (between $3.0 \mathrm{~m}$ in the $3^{\text {rd }}$ floor and $6.70 \mathrm{~m}$ in the case of double volume rooms) as well as the typology of the slabs: different vaulted surfaces (cross, barrel and cloister vaults in some cases with lunettes) and different horizontal slabs (with wooden, steel, woodensteel and r.c. elements) are present. A detailed geometrical and structural survey 
of the building was executed, allowing to obtain a very deep knowledge of the structural aggregate and of its parts.

\subsection{In situ investigations and survey}

A deep in situ survey campaign was executed, in the case of both Palazzo La Sapienza and Palazzo Ducale, aiming to determine the typologies of vertical bearing walls, horizontal floors (both storey slabs and vaulted surfaces) and the roof structure. Endoscopic analyses were executed on masonry walls in order to determine the masonry typology, the possible presence of cavities and the level of connections between perpendicular walls (Figure 6). Experimental in situ tests using double flat-jacks were also executed evaluating the mechanical properties of masonry to adopt for safety checks. Structural survey of horizontal floors, analyzing the shape, material and dimension of bearing elements (wooden, steel or r.c. elements) and the thickness of the slab including concrete, pavement, masonry lightening blocks and other (Figure 7) were finally conducted.
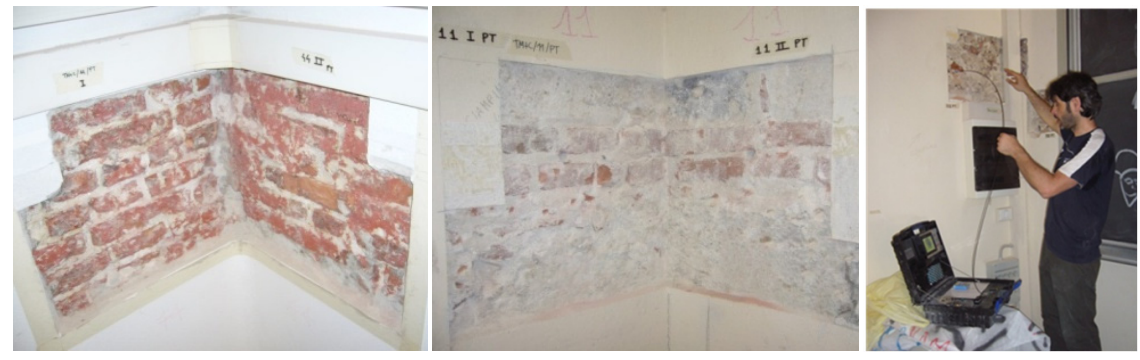

Figure 6: Endoscopic investigations on masonry walls (Palazzo La Sapienza).

(a)
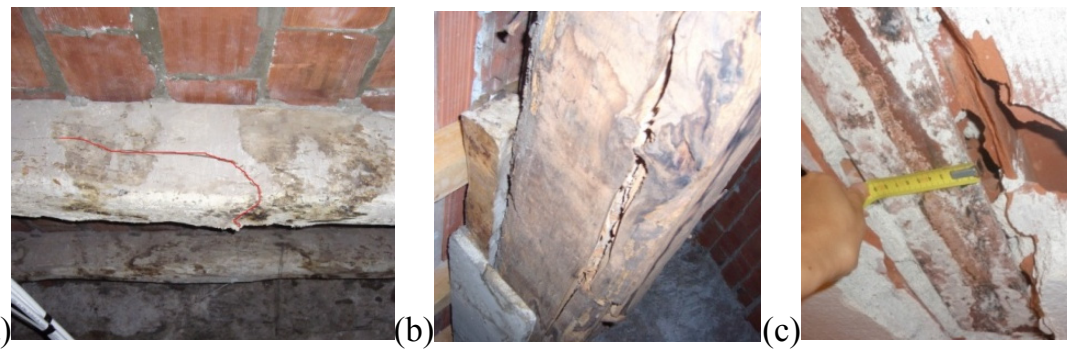

Figure 7: (a)-(b) Wooden elements of floors (Palazzo Ducale), (c) steel IPN profile (Palazzo La Sapienza).

Geotechnical investigations were executed on foundation structures and on the subsoil, allowing to determine the shape and dimensions the foundation system, its disposition under the ground floor level and, moreover, the soil category necessary to define local seismic action.

A detail survey of the cracking scenario was also executed. The analysis of the cracking scenario and of its relationship with the progressive evolution of the 
building, its modifications, enlargements and super-elevations, allows the determination of the effective acting movement and of the development of the damage scenario. For what concerns Palazzo La Sapienza, as a consequence of the cracking scenario survey, two monitoring systems - one periodic and one continuous - were organized and installed in order to determine the possible evolution of the ongoing subsidence and disruptions (Figure 8). The analysis of the monitoring results allowed the identification of the areas characterized by differential displacements, such as, for instance, in correspondence to the vaults of the ground floor colonnade and first floor arcade.

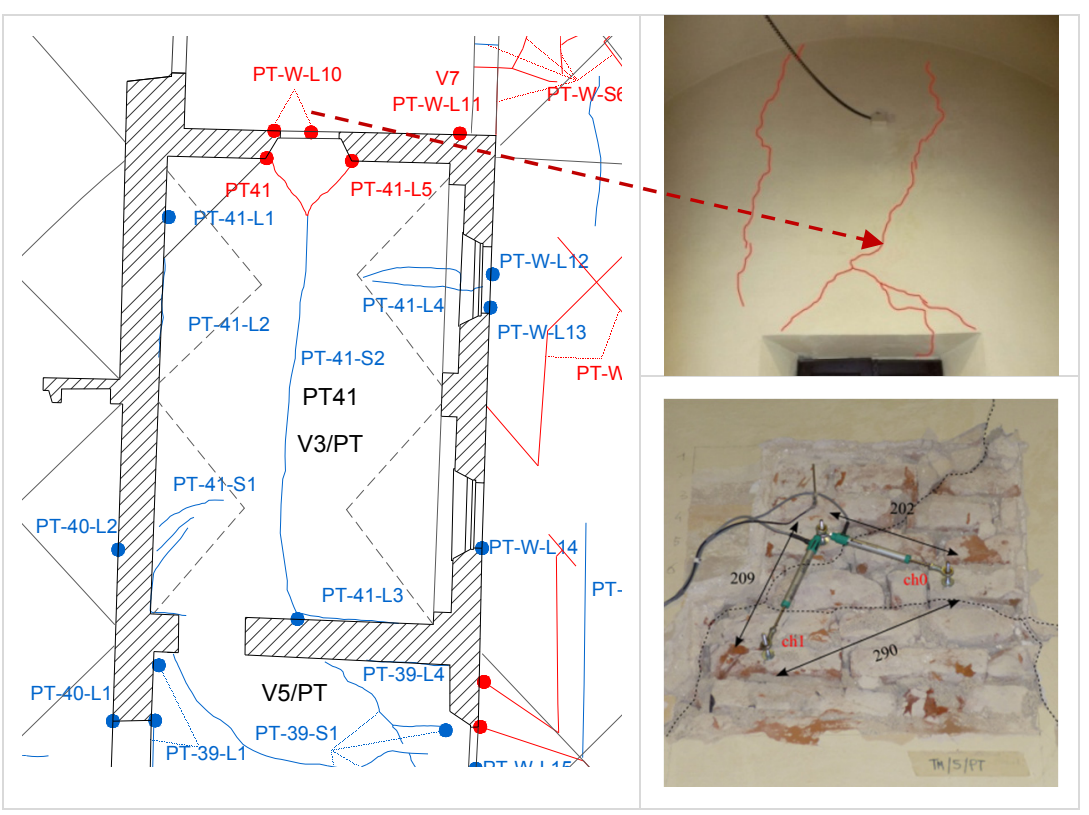

Figure 8: Example of the cracking scenario of Palazzo La Sapienza and installation of the monitoring system.

Similar investigations were executed in correspondence of the masonry walls and vaulted surfaces of Palazzo Ducale. The cracking scenario affecting the historical building was revealed just from its constructions, due to the progressive enlargement of the structure itself. In recent years, the building suffered the consequences of the Emilia-Romagna earthquake (5.8 and 5.9 Richter, respectively in the dates 20.05 .2012 and 29.05.2012), that was the cause of the beginning of vulnerability assessment and analysis of the actual state of the palace. The first cracking survey was executed in the period between July and September 2012, while four additional campaigns were executed until July 2013, after the earthquake that stroke the near region of Lunigiana (4.4 Richter, 13.06.2013). The results of the survey of the evolution of the in situ cracking scenario, in the period July 2012-July 2013, is simply represented in the Figure 9 for one of the main 
rooms of the ground floor of the building. The analysis of the cracking scenario allowed the individuation of the most critical portions of the Palace, and the following organization of monitoring and local repair measures.

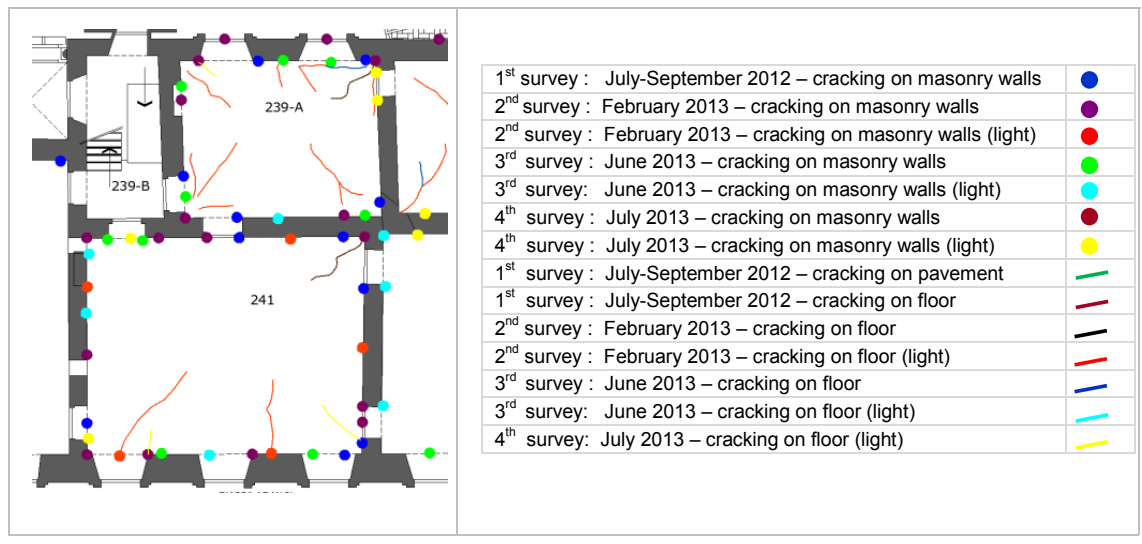

Figure 9: Example of the evolution of the cracking scenario in Palazzo Ducale during the period July 2012-July 2013.

\section{Vulnerability analysis and individuation of criticisms}

The actual Italian standard for Constructions D.M.14/01/2008 [1] together with the Guidelines of the Ministry of Culture and Heritage [10] prescribe the execution of safety checks on existing masonry buildings considering, in parallel, global and local verifications of single bearing elements (i.e. vertical masonry walls, horizontal floors, roof elements and vaulted surfaces) and of portions of the historical building for which the activation of local collapse failures (i.e. overturning of corners, of facades, of galleries and others) seems to be possible in relation to the deep investigation of the actual in-situ conditions including cracking scenarios, evolutive analysis and so on. The elaboration of a global numerical model necessary for the execution of safety verifications shall be then coupled with the analysis of the possible local collapse mechanisms.

\subsection{Global analysis of the buildings}

Very complex buildings like the ones analyzed in the present work shall be considered more similar to structural aggregates than to single buildings, made up of different parts/units connected together during the centuries. The difficulty in the modelling of material discontinuities, disconnections between perpendicular walls and others leads to the elaboration of global numerical models representative of an improved condition of the structural system.

The linear three-dimensional FEM models of the buildings (Figure 10) were realized using SAP 2000, adopting two-dimensional elements for the walls and one-dimensional elements for the profiles of the floor slabs and of the roof. The vaulted surfaces were modelled with equivalent two-dimensional plane elements. 
The mechanical characteristics of the masonry material were selected according to the results of in situ flat-jack tests and to the indications contained in the Circ. $617 / 2009$ [12], for the different types of masonry pattern. The presence of cracking phenomena was conventionally taken into consideration through the reduction of the stiffness of the masonry walls [1, 13]. The interaction between the superstructure and the ground soil was represented through the Winkler model, with elastic three-directional springs calibrated according to the results of the geotechnical investigations; the horizontal stiffness was assumed equal to the $25 \%$ of the vertical one. Linear modal analysis was executed on the three dimensional models of the two buildings, after a detailed investigation of the vertical and horizontal loads acting on the building (including gravitational, dead loads and seismic action, evaluated if possible through local response analysis, like in the case of Palazzo La Sapienza [14]). The results of analysis for each bearing element were used for the static and vulnerability assessment through the application of D.M.14/01/2008 [1] prescriptions. Global safety checks (i.e. shear, bending and compression in and out of plane) were executed for Palazzo La Sapienza and are still in execution in the case of Palazzo Ducale. In the case of Palazzo La Sapienza, the global checks on masonry walls evidenced that the building essentially satisfies the safety requirements with regard to both static and seismic actions, with the exception of extremely small-sized, slender elements characterized by a considerable heterogeneity in shape and materials and by extensive cracking due to the progressive structural layering and modifications made to the building. Floors and vaults, with the exception of an under-dimensioned slab on the building's $2^{\text {nd }}$ floor, did not evidence significant structural deficiencies in terms of either strength or deformability. The wooden roofing structures presented a widespread degradation and consequently often did not satisfy the safety requirements.

(a)

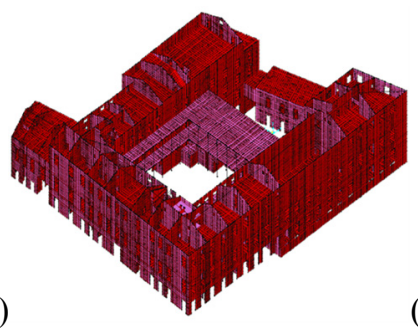

(b)

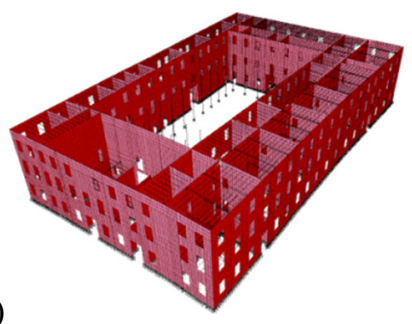

Figure 10: Global FEM models of (a) Palazzo Ducale and (b) Palazzo La Sapienza.

\subsection{Analysis of local collapse mechanisms}

Linear kinematic analysis was adopted for the determination of the value of horizontal Peak Ground Acceleration (PGA) able to activate the considered collapse mechanism, to be compared with the design reference value in order to assess the level of safety achieved by the building. The analyzed collapse mechanisms were selected in relation to the results of geometrical, structural and 
of the cracking scenario surveys, that evidenced the most significant criticisms developed in the buildings.

For what concerns Palazzo La Sapienza, the analysis of the possible overturning of the internal masonry wall of the court $\left(1^{\text {st }}\right.$ and $2^{\text {nd }}$ floor parallel to Piazza Dante, due to the removing of perpendicular retaining walls in relation to increasing necessities of the library) and of the external wall of the New Great Hall (double volume, $1^{\text {st }}$ floor - Via Curtatone and Montanara) were executed (Figure $11)$.

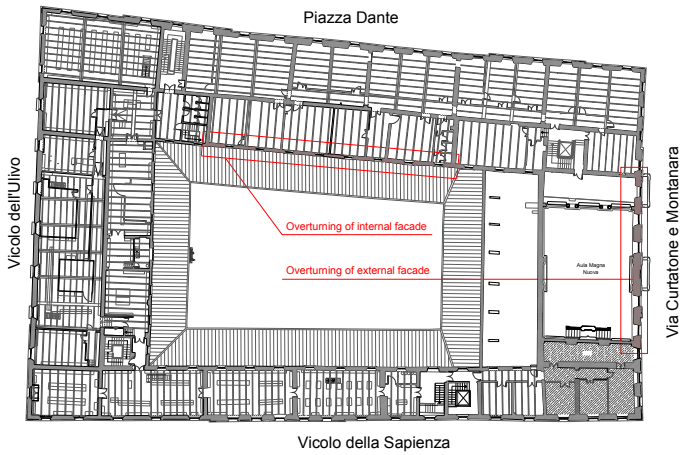

Figure 11: Possible local collapse mechanisms for Palazzo La Sapienza (Pisa).

In the first case, the internal masonry wall is not provided by perpendicular retains, resulting in the possibility to activate the global overturning of the wall both at first and second level. The PGA leading to the activation of the collapse overturning mechanism are respectively equal to $0.060 \mathrm{~g}$ and $0.079 \mathrm{~g}$ for the $1^{\text {st }}$ and the $2^{\text {nd }}$ floor, towards a foreseen design PGA equal, for the considered site, to $0.118 \mathrm{~g}$, evidencing the possible activation the local failure and the following necessity to organize retrofit intervention towards horizontal actions. Similar considerations can be executed also for the external wall of the New Great Hall, characterized by a double vaulted surface and the absence of perpendicular restraints, with the following activation of the overturning mechanisms for PGA equal to $0.112 \mathrm{~g}$ respect the foreseen design one of $0.118 \mathrm{~g}$.

For what concerns Palazzo Ducale, the execution of in situ experimental survey on masonry walls evidenced the lack or the inadequacy of the connection between the perpendicular masonry vertical elements and, at the same time, the reduced dimensions of the façade portions, whose overturning mechanisms were then evaluated (Figure 12). The PGA levels associated to the activation of the local failure are lower than the design one (i.e. $0.171 \mathrm{~g}$ ), and variable between $0.060 \mathrm{~g}$ and $0.137 \mathrm{~g}$.

\section{Conclusions}

According to what presented in the previous paragraphs, the analysis of complex historical buildings such as Palazzo La Sapienza in Pisa and Palazzo Ducale in 
Massa shall be executed considering the construction not as a single unit but as structural aggregates, made up of different parts realized at different times and connected together adopting various different techniques. The aforementioned

(a)

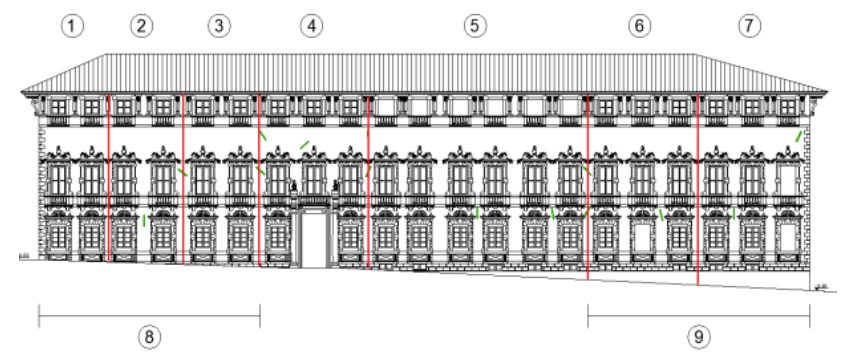

(b)

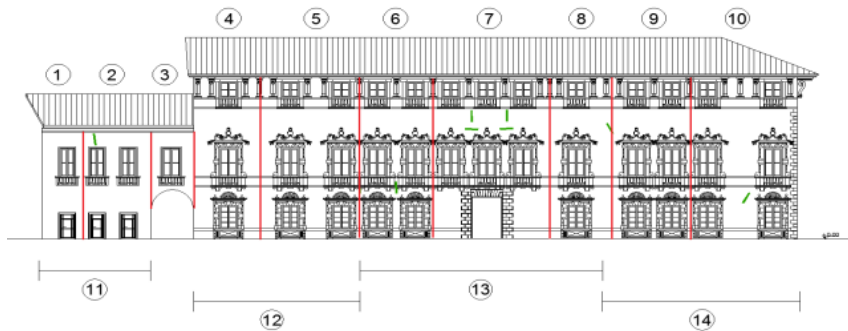

(c)

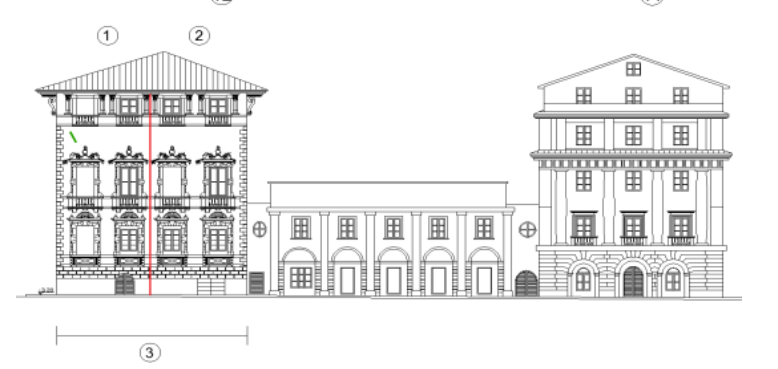

Figure 12: Local collapse mechanism of the façades towards (a) Piazza Aranci, (b) Via Guidoni and (c) Via Alberica.

complexity and structural heterogeneity are usually translated into differences in the structural response and performance, consequently requiring detailed analyses of every single portion of the building and of its conditions of use, management and functional aspects. The structural analysis of the two historical buildings was therefore performed considering in parallel the global behaviour of the structure and the behaviour of particularly significant sub-portions of building, subjected to the possible activation of local collapse mechanisms (for example out-of-plane tilting and overturning of façades or corners, horizontal thrusts due to vaults and roofing structures, presence of intermediary mezzanines with mechanisms of simple bending, etc.). A critical evaluation of the building's safety, together with a clear, deep understanding and knowledge of the structure itself, constitute the 
basis to define the objective of any structural interventions, carefully designed to achieve appropriate safety levels, durability of relevant portions of the building and, at the same time, produce the least impact possible on this important living example of Italy's historical heritage.

\section{References}

[1] NTC2008. D. M. Infrastrutture Trasporti 14 gennaio 2008, Norme Tecniche per le Costruzioni, (In Italian), 2008.

[2] European standard EN1998-3. Eurocode 8: design provisions for earthquake resistance of structures - Part 3: assessment and retrofitting of buildings. European Committee for Standardization, Brussels, 2005.

[3] FEMA 547. Techniques for the Seismic Rehabilitation of Existing Buildings. Federal Emergency Management Agency, Washington DC, 2006.

[4] G. Barbieri, L. Biolzi, M. Bocciarelli, L. Fregonese, A. Frigeri, A. Assessing the seismic vulnerability of a historical building. Engineering Structures, 57, pp. 523-535, 2013.

[5] V. Mallardo, R. Malvezzi, E. Milani, G. Milani. Seismic vulnerability of historical masonry buildings: a case study in Ferrara. Engineering Structures, 30, pp. 2223-2241, 2008.

[6] G. Chellini, L. Nardini, B. Pucci, W. Salvatore, R. Tognaccini. Evaluation of seismic vulnerability of Santa Maria del Mar in Barcelona by an integrated approach based on terrestrial laser scanner and finite element modelling. International Journal Architectural Heritage, 8(6), pp.795-819, 2014.

[7] S. Lagomarsino. On the vulnerability assessment of monumental buildings. B Bulletin of Earthquake Engineering, 4, pp. 445-463, 2006.

[8] A. Bernardini, S. Lagomarsino. The seismic vulnerability of architectural heritage. In Proceedings of the Institution of Civil Engineers - Structures \& Buildings, 161 (SB4): pp. 171-181.

[9] C.S. Oliveira. Seismic Vulnerability of Historical Constructions: A Contribution. Bulletin of Earthquake Engineering, 1, pp. 37-82, 2003.

[10] Linee Guida per la valutazione e riduzione del rischio sismico del patrimonio culturale allineate alle nuove Norme Tecniche per le Costruzioni (D.M. 14/01/2008), 2010.

[11] W. Salvatore, P. Iannelli. Verifica della sicurezza statica ed analisi della vulnerabilità sismica dell'edificio La Sapienza di Pisa, Report University of Pisa and MiBACT, 2013.

[12] Circ. n617/2009 "Istruzioni per l'applicazione delle "Norme tecniche per le costruzioni” di cui al D.M. 14 gennaio 2008” (in Italian), 2009.

[13] T. Paulay, M.J.N. Priestley. Seismic design of reinforced concrete and masonry buildings. John Wiley and sons, INC. New York, USA, 1991.

[14] S. Caprili, F. Mangini, W. Salvatore, G. Scarpelli, N. Squeglia "Influence of soil-foundation-structure interaction on overall behaviour and diseases of a medieval building in Pisa" 14th International Conference on Studies, Repairs and Maintenance of Heritage Architecture, La Corunha, 13-15 July 2015. 